\title{
Sociodemographic Factors Associated With Rapid Relapse in Triple-Negative Breast Cancer: A Multi-Institution Study
}

\author{
Sarah Asad, MPH${ }^{1}$; Carlos H. Barcenas, MD, MS²; Richard J. Bleicher, MD³; Adam L. Cohen, MD, MS ${ }^{4}$; Sara H. Javid, MD; \\ Ellis G. Levine, MD; Nancy U. Lin, MD; Beverly Moy, MD, MPH${ }^{8}$; Joyce Niland, PhD ${ }^{6}$; Antonio C. Wolff, MD ${ }^{10}$; \\ Michael J. Hassett, MD, MPH${ }^{7}$; and Daniel G. Stover, $\mathrm{MD}^{1}$
}

\begin{abstract}
Background: Triple-negative breast cancer (TNBC) accounts for disproportionately poor outcomes in breast cancer, driven by a subset of rapid-relapse TNBC ( $r$ TNBC) with marked chemoresistance, rapid metastatic spread, and poor survival. Our objective was to evaluate clinicopathologic and sociodemographic features associated with rrTNBC. Methods: We included patients diagnosed with stage I-III TNBC in 1996 through 2012 who received chemotherapy at 1 of 10 academic cancer centers. rrTNBC was defined as a distant metastatic recurrence event or death $\leq 24$ months after diagnosis. Features associated with $\operatorname{rrTNBC}$ were included in a multivariable logistic model upon which backward elimination was performed with a $P<.10$ criterion, with a final multivariable model applied to training (70\%) and independent validation (30\%) cohorts. Results: Among all patients with breast cancer treated at these centers, 3,016 fit the inclusion criteria. Training cohort $(n=2,112)$ bivariable analyses identified disease stage, insurance type, age, body mass index, race, and income as being associated with $\operatorname{rrTNBC}(P<.10)$. In the final multivariable model, rrTNBC was significantly associated with higher disease stage (adjusted odds ratio for stage III vs I, 16.0; $95 \% \mathrm{Cl}$, 9.8-26.2; $P<.0001)$, Medicaid/indigent insurance, lower income (by 2000 US Census tract), and younger age at diagnosis. Model performance was consistent between the training and validation cohorts. In sensitivity analyses, insurance type, low income, and young age were associated with $\operatorname{rrTNBC}$ among patients with stage I/II but not stage III disease. When comparing rrTNBC versus late relapse ( $>24$ months), we found that insurance type and young age remained significant. Conclusions: Timing of relapse in TNBC is associated with stage of disease and distinct sociodemographic features, including insurance type, income, and age at diagnosis.
\end{abstract}

J Natl Compr Canc Netw 2021;19(7):797-804 doi: $10.6004 /$ jnccn.2020.7659

\footnotetext{
${ }^{1}$ Ohio State University Wexner Medical Center, Columbus, Ohio; ${ }^{2} \mathrm{MD}$ Anderson Cancer Center, Houston, Texas; ${ }^{3}$ Fox Chase Cancer Center Philadelphia, Pennsylvania; ${ }^{4}$ University of Utah, Salt Lake City, Utah; ${ }^{5}$ Seattle Cancer Care Alliance, Seattle, Washington; ${ }^{6}$ Roswell Park Comprehensive Cancer Center, Buffalo, New York; ${ }^{7}$ Dana-Farber Cancer Institute, and ${ }^{8}$ Massachusetts General Hospital, Boston, Massachusetts; ${ }^{9}$ City of Hope National Medical Center, Duarte, California; and ${ }^{10}$ Johns Hopkins University, Baltimore, Maryland.
}

\section{Background}

Triple-negative breast cancer (TNBC) is defined by a lack of targetable estrogen receptor (ER), progesterone receptor (PR), and HER2. TNBC accounts for a disproportionate amount of poor outcomes among patients with breast cancer, constituting $10 \%$ to $15 \%$ of breast cancers yet accounting for $>35 \%$ of breast cancerrelated deaths. ${ }^{1}$ Relative to other breast cancer subsets, TNBCs tend to present with a higher T stage ${ }^{2}$ and spread more frequently to visceral sites, including the lungs and brain, and less frequently to bone., ${ }^{2,3}$ Understanding the determinants of distant relapse is critical because survival for patients with TNBC after metastatic diagnosis ranges from $17^{3,4}$ to 25 months. ${ }^{5}$

Most metastatic recurrences of TNBC occur within 5 years of diagnosis, ${ }^{1,6}$ although later recurrences are increasingly of interest. ${ }^{7}$ Among all TNBC recurrences, a subset exhibits a particularly aggressive course with marked chemoresistance, rapid distant metastatic spread, and relapse of disease or death. ${ }^{8-10}$ In several large TNBC cohort studies, the median time to distant metastasis was approximately 2 years, ranging from 19.7 to 31.2 months., ${ }^{3,611,12}$ Therefore, to investigate this aggressive subset of TNBCs, we define rapid-relapse TNBC (rrTNBC) as relapse or death within 24 months of diagnosis.

The determinants of rrTNBC and what distinguishes rapid relapse from later relapse remain unknown. Because there was not a single adequately large dataset that included both genomic data and detailed sociodemographic data, we undertook concurrent studies evaluating both biological and nonbiological determinants of rrTNBC. In a parallel study, we investigated the association of multi-omic and clinical features with rrTNBC among 453 primary TNBCs ${ }^{13}$ and successfully

See JNCCN.org for supplemental online content. 
identified transcriptional programs and genomic alterations associated with rrTNBC. However, that study found that stage at diagnosis remained among the top contributing features in multiple modeling approaches in the context of tens of thousands of genomic features. Stage at diagnosis is known to be associated with both biological features and sociodemographic features, such as race, insurance type, income, and education level. ${ }^{14-19}$

The primary objective of the present study was to evaluate clinicopathologic and sociodemographic features associated with rrTNBC.

\section{Methods}

\section{Patients}

In this large multi-institutional study, we analyzed a cohort of patients diagnosed with TNBC who received treatment at 1 of 10 academic centers that previously participated in an NCCN outcomes database in 1996 through 2012 (City of Hope National Medical Center, Dana-Farber Cancer Institute, Fox Chase Cancer Center, The Sidney Kimmel Comprehensive Cancer Center at Johns Hopkins, Massachusetts General Hospital Cancer Center, The University of Texas MD Anderson Cancer Center, The Ohio State University Comprehensive Cancer Center - James Cancer Hospital and Solove Research Institute, Roswell Park Comprehensive Cancer Center, University of Washington/Seattle Cancer Care Alliance, and Huntsman Cancer Institute at the University of Utah). Prospective diagnosis, treatment, and outcomes data were collected from medical records and tumor registries by abstractors using procedures developed by NCCN. TNBC was defined as being "negative" or "unknown/missing" for both ER and PR (patients with "unknown/missing" for both ER and PR were excluded) and having an HER2 immunohistochemistry value that was 0 , negative, or $1+$ (with no fluorescence in situ hybridization [FISH]) or being FISH-negative.

rrTNBC was defined as distant metastatic recurrence or death from any cause $\leq 24$ months after diagnosis based on large TNBC cohort studies., ${ }^{3,6,11,12}$ We included only patients with $\geq 24$ months follow-up or those who had a survival event within that time frame, and excluded those with de novo metastatic disease. We also excluded patients who did not receive chemotherapy within 9 months of diagnosis, and included those who received either neoadjuvant or adjuvant chemotherapy. The 592 patients were excluded because they did not receive chemotherapy, were more likely to be aged $>60$ years at diagnosis and White, had less education, and had a higher comorbidity score. Furthermore, these patients were more likely to have Medicare insurance, a lower stage at diagnosis, and a lower histologic grade (data available upon request). These investigations were performed after approval by the Institutional Review Board of Ohio State University and all participating sites. All centers adhered to the data collection procedures and definitions developed for the NCCN database and that have been subjected to rigorous quality assurance. ${ }^{20}$

\section{Statistical Analyses}

The dataset was randomly divided into $70 \%$ training and $30 \%$ validation cohorts via simple random sampling stratified by relapse status. Descriptive comparisons between clinical and pathologic features were conducted using the chi-square test. Covariates of interest included study site, age at diagnosis by decade, body mass index (BMI), race/ethnicity, education level, median annual household income based on 2000 US Census tract, ${ }^{21}$ insurance type, Charlson comorbidity index, tumor stage and histologic grade at diagnosis, and adjuvant radiation therapy. Insurance type was categorized as managed care, Medicare, Medicaid/indigent (including dualeligible patients), and other, which included patients with self-pay and indemnity insurance. Bivariable logistic regression was performed among the training dataset for associations between each covariate of interest (ie, rrTNBC vs non-rrTNBC). Features with a $P$ value $<.10$ were included in a multivariable logistic regression model. Backward selection was performed on the multivariable model with a $P<.10$ criterion to identify the final multivariable model. The final model included tumor stage, income, insurance type, and age at diagnosis. Interactions between covariates were not evaluated. A sensitivity analysis of the final model was performed to confirm that the calculated odds ratios approximated risk ratios (supplemental eTable 1, available with this article at JNCCN.org).

Bootstrapping was performed on the final model to establish coefficients, and the bootstrapped coefficients were applied to the training and independent validation cohorts. Model performance of the final bootstrapped model was assessed in the training and validation cohorts using receiver operating characteristic (ROC) curves with area under the curve (AUC) statistics; ROC curves compare sensitivity to specificity across a range of values, assessing a model's ability to predict a binary outcome. A sensitivity analysis was performed on patients with at least 60 months follow-up or a relapse event to evaluate rrTNBC versus late relapse (defined as distant metastasis or disease-specific mortality $>24$ months from diagnosis). We performed a stratified sensitivity analysis to assess the final model among patients with stage I and stage II disease combined versus those with stage III disease. Finally, we created a directed acyclic graph, with rrTNBC as the outcome and tumor stage as the main predictor, to evaluate associations between 
covariates given the complex interplay of sociodemographic variables.

\section{Results}

Among 41,839 patients with invasive breast cancer treated at the 10 centers during the study period, 5,256 had TNBC (12.6\%); of these patients, 3,016 fit criteria to be included in the analysis (Figure 1). After the random split, the training cohort included 2,112 patients and the independent validation cohort included 904. Demographic features were balanced between the training and validation cohorts (Table 1, supplemental eTable 2). Median time to relapse in the total cohort was 19.7 months, which is similar to that of large published cohorts., ${ }^{3,6,11,12}$ Overall, $16.9 \%(n=509)$ of included patients with TNBC had rrTNBC. These patients were more likely to be younger and non-White, have less education and lower income, have Medicare or Medicaid/indigent insurance, and have a higher disease stage at diagnosis compared with those who did not have rrTNBC (supplemental eTable 2).

Bivariable analyses in the training cohort $(n=2,112)$ identified tumor stage at diagnosis, insurance type, age at diagnosis, BMI, race/ethnicity, and income to

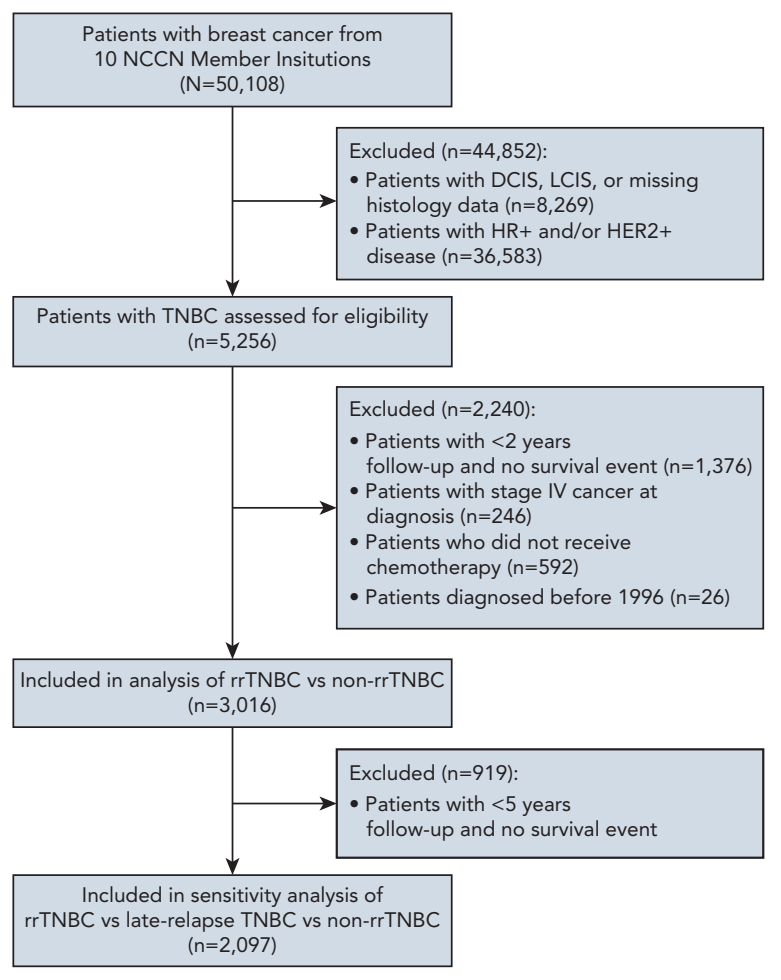

Figure 1. CONSORT diagram.

Abbreviations: DCIS, ductal carcinoma in situ; HER2+, HER2-positive; $\mathrm{HR}+$, hormone receptor-positive; LCIS, lobular carcinoma in situ; rrTNBC, rapid-relapse triple-negative breast cancer; TNBC, triple-negative breast cancer. be associated with rrTNBC events using our prespecified cutpoint of $P<.10$ (supplemental eTable 3 ). Specifically, rrTNBC was associated with higher stage at diagnosis, Medicaid/indigent and Medicare insurance types, older age at diagnosis, higher BMI, non-Hispanic Black race, and lower median annual household income. Study site, comorbidity score, education, histologic grade, and receipt of radiation were not significantly associated with rTNBC in bivariable analyses.

The multivariable model identified tumor stage, insurance type, income, BMI, and age at diagnosis as significant contributors (supplemental eTable 3). In the final model (Table 2), stage at diagnosis was the most significant factor, with patients presenting with stage III disease having a $>15$ times increased odds of rrTNBC (adjusted odds ratio [aOR], 16.0; 95\% CI, 9.8-26.2; $P<.0001)$ compared with those presenting with stage I disease. Patients with stage II disease also had an increased odds of rrTNBC compared with those with stage I disease (aOR, 3.3; 95\% CI, 2.0-5.4; $P<.0001$ ). In addition, patients with Medicaid/indigent insurance (aOR, 1.6; 95\% CI, 1.1-2.4; $P=.01$ ) versus those with managed care insurance were significantly more likely to develop rrTNBC. Patients aged $<50$ years had increased odds of rrTNBC (aOR, 1.4; 95\% CI, 0.9-2.1; $P=.09$ ), although the odds were not statistically significant. Race/ethnicity did not remain significant in the final model. Model performance of the final bootstrapped model resulted in an AUC of 0.762 (95\% CI, 0.735-0.790) for the training cohort and 0.771 (95\% CI, 0.729-0.812) for the independent validation cohort (Figure 2).

To understand whether the effects seen varied by stage, we performed a stratified analysis by stage. Among patients with stage I and II disease, Medicare or Medicaid/indigent insurance, lower income, and younger age at diagnosis were significantly associated with increased odds of rrTNBC; however, among patients with stage III disease, insurance type, income, and age at diagnosis were not significantly associated with rrTNBC (Table 3).

For this sensitivity analysis, we only included patients with at least 5 years follow-up or a relapse event $>24$ months after diagnosis (Figure 1). Among the variables included in the final multivariate model, we found that there were significant differences between rrTNBC and late-relapse TNBC in insurance type, age at diagnosis, and stage at diagnosis but not median annual household income (by 2000 US Census tract). ${ }^{21}$ Specifically, patients with rrTNBC had a greater percentage of Medicaid/indigent coverage, whereas those with late-relapse TNBC had a greater percentage of Medicare coverage (Table 4). This finding corresponded with age at diagnosis, with late-relapse TNBC associated with 


\section{Table 1. Patient Characteristics}

\begin{tabular}{|c|c|c|c|c|}
\hline & $\begin{array}{l}\text { Overall } \\
\mathrm{n}(\%)\end{array}$ & $\begin{array}{c}\text { Training Cohort } \\
\mathbf{n}(\%)\end{array}$ & $\begin{array}{c}\text { Validation Cohort } \\
\mathrm{n}(\%)\end{array}$ & $\begin{array}{c}\text { Chi-Square } \\
P \text { Value }\end{array}$ \\
\hline Patients, N & 3,016 & 2,112 & 904 & \\
\hline Age at diagnosis, $y$ & & & & .70 \\
\hline$<50$ & $1,432(47.5)$ & $1,000(47.4)$ & $432(47.8)$ & \\
\hline $50-59$ & $905(30.0)$ & $625(29.6)$ & $280(31.0)$ & \\
\hline $60-69$ & $514(17.0)$ & $370(17.5)$ & $144(15.9)$ & \\
\hline$\geq 70$ & $165(5.5)$ & $117(5.5)$ & $48(5.3)$ & \\
\hline Race/Ethnicity & & & & .93 \\
\hline White, non-Hispanic & $2,171(72.6)$ & $1,517(72.5)$ & $654(72.8)$ & \\
\hline Black, non-Hispanic & $437(14.6)$ & $305(14.6)$ & $132(14.7)$ & \\
\hline Hispanic/Other & $384(12.8)$ & $272(13.0)$ & $112(12.5)$ & \\
\hline Education level & & & & .87 \\
\hline$<$ High school & $183(7.5)$ & $133(7.8)$ & $50(6.8)$ & \\
\hline High school & $604(24.9)$ & $422(24.8)$ & $182(24.9)$ & \\
\hline Some college, vocational/technical school & $692(28.5)$ & $482(28.4)$ & $210(28.7)$ & \\
\hline College or higher & $952(39.2)$ & $663(39.0)$ & $289(39.5)$ & \\
\hline Median annual household income, USD & & & & .80 \\
\hline Quartile 1 & $726(25.0)$ & $509(25.0)$ & $217(24.9)$ & \\
\hline Quartile 2 & $722(24.9)$ & $504(24.8)$ & $218(25.1)$ & \\
\hline Quartile 3 & $728(25.1)$ & $519(25.5)$ & $209(24.0)$ & \\
\hline Quartile 4 & $727(25.0)$ & $501(24.6)$ & $226(26.0)$ & \\
\hline Insurance type & & & & .34 \\
\hline Managed care & $2,153(72.1)$ & 1,493 (71.3) & $660(73.9)$ & \\
\hline Medicare & $377(12.6)$ & $275(13.1)$ & $102(11.4)$ & \\
\hline Medicaid/Indigent & $257(8.6)$ & $188(9.0)$ & $69(7.7)$ & \\
\hline Other & $199(6.7)$ & $137(6.6)$ & $62(6.9)$ & \\
\hline BMI, $\mathrm{kg} / \mathrm{m}^{2}$ & & & & .15 \\
\hline$<18.5$ & $254(8.4)$ & $180(8.5)$ & $74(8.2)$ & \\
\hline $18.5-24.9$ & 919 (30.5) & $667(31.6)$ & $252(27.9)$ & \\
\hline $25.0-29.9$ & $860(28.5)$ & $582(27.6)$ & $278(30.8)$ & \\
\hline$\geq 30.0$ & $983(32.6)$ & $683(32.3)$ & $300(33.2)$ & \\
\hline Comorbidity score & & & & .57 \\
\hline 0 & $2,376(78.8)$ & $1,654(78.3)$ & 722 (79.9) & \\
\hline 1 & 420 (13.9) & $303(14.4)$ & 117 (12.9) & \\
\hline$\geq 2$ & $220(7.3)$ & $155(7.3)$ & $65(7.2)$ & \\
\hline Stage at diagnosis & & & & .77 \\
\hline I & 775 (25.7) & $538(25.5)$ & $237(26.2)$ & \\
\hline ॥ & $1,558(51.7)$ & $1,100(52.1)$ & $458(50.7)$ & \\
\hline III & $683(22.7)$ & $474(22.4)$ & 209 (23.1) & \\
\hline Histologic grade & & & & .34 \\
\hline 1 & $15(0.7)$ & $8(0.5)$ & $7(1.1)$ & \\
\hline 2 & $212(9.7)$ & $145(9.5)$ & $67(10.2)$ & \\
\hline 3 & $1,956(89.6)$ & $1,370(90.0)$ & $586(88.8)$ & \\
\hline
\end{tabular}

Abbreviation: $\mathrm{BMI}$, body mass index.

${ }^{a}$ Calculated with 2000 US Census. ${ }^{21}$ 


\begin{tabular}{|c|c|c|}
\hline Correlate & aOR $(95 \% \mathrm{Cl})$ & $P$ Value \\
\hline \multicolumn{3}{|l|}{ Insurance type } \\
\hline Managed care & Ref & \\
\hline Medicare & $1.5(0.9-2.4)$ & .14 \\
\hline Medicaid/Indigent & $1.6(1.1-2.4)$ & .01 \\
\hline Other & $0.97(0.5-1.8)$ & .93 \\
\hline \multicolumn{3}{|c|}{ Median annual household income, USD } \\
\hline Quartile 1 & $1.5(1.0-2.2)$ & .04 \\
\hline Quartile 2 & $1.1(0.7-1.6)$ & .66 \\
\hline Quartile 3 & $1.3(0.9-1.9)$ & .14 \\
\hline Quartile 4 & Ref & \\
\hline \multicolumn{3}{|l|}{ Age at diagnosis, y } \\
\hline$<50$ & $1.4(0.9-2.1)$ & .09 \\
\hline $50-59$ & $0.95(0.6-1.5)$ & .82 \\
\hline $60-69$ & Ref & \\
\hline$\geq 70$ & $0.94(0.5-1.7)$ & .85 \\
\hline \multicolumn{3}{|l|}{ Stage at diagnosis } \\
\hline 1 & Ref & \\
\hline II & $3.3(2.0-5.4)$ & $<.0001$ \\
\hline III & $16.0(9.8-26.2)$ & $<.0001$ \\
\hline
\end{tabular}

Abbreviation: aOR, adjusted odds ratio.

${ }^{a}$ Calculated with 2000 US Census. ${ }^{21}$

older age and rrTNBC associated with younger age. rrTNBC was associated with a greater percentage of patients $(55 \%)$ with stage III disease at diagnosis, and late-relapse TNBC had nearly $70 \%$ of patients diagnosed with stage I-II disease.

\section{Discussion}

TNBC is associated with a disproportionate contribution to breast cancer mortality relative to other breast cancer subtypes. ${ }^{1}$ Approximately half of distant recurrences occur within 2 years of diagnosis, based on several large TNBC cohort studies., ${ }^{3,6,11,12}$ Although the timing of relapse is of great interest in the breast cancer field, most investigations have focused on late recurrence $\geq 5$ years after diagnosis, which is more common in ER-positive/HER2-negative breast cancer. ${ }^{22-24}$ Factors associated with timing of relapse are not well studied in TNBC, possibly because of smaller overall numbers and because most recurrences occur within the first 5 years after diagnosis.

In this study, we found that rrTNBC was associated with a higher stage at diagnosis, younger age at diagnosis, and Medicaid or no insurance (indigent). Our sensitivity analysis of rrTNBC versus late-relapse TNBC, with a similar number of events in both groups, suggested that these findings are not just associated with TNBC relapse in general, but are specific to rrTNBC. Furthermore, our findings support a prior study that suggests that later relapse in TNBC is associated with older age and postmenopausal status. ${ }^{7}$

Our findings reinforce the complex interaction between stage at diagnosis and sociodemographic factors. Within this cohort, BMI, race, income, insurance type, and age at diagnosis were all associated with stage and rrTNBC (supplemental eFigure 1). Unsurprisingly, stage at diagnosis was the feature most strongly associated with rrTNBC in all analyses, with patients who presented with stage III disease having a $>15$ times increased odds of rrTNBC compared with those who presented with stage I disease. Despite this finding, most patients with stage III disease did not relapse rapidly (385/683; 56.4\%), suggesting that one cannot rely on stage alone. In our stage-stratified analysis, sociodemographic variables including Medicare or Medicaid/indigent insurance, low income, and young age were associated with rrTNBC only among patients with stage I or II disease. This suggests that among patients with early-stage disease who experience relapse, sociodemographic factors play a significant role in the timing of relapse, but for patients with late-stage disease who experience relapse, the timing of relapse is driven primarily by stage. Furthermore, it seems that stage at diagnosis is influenced not only by underlying biology but also by sociodemographic factors. Multiple studies have suggested that patients with breast cancer with lower income, Medicaid or no insurance, less education, and less access to care are significantly more likely to present with a higher stage of cancer. ${ }^{17,25-28}$ The findings in our study support these conclusions, as visualized in our directed acyclic graph. Interestingly, although we found that income and insurance were associated with both rrTNBC and stage at diagnosis, education was not associated with rrTNBC in the bivariable analyses. Collectively, these data suggest that among stage I/II TNBCs there may be factors, such as insurance and income, that can identify patients at high risk of rrTNBC.

The impact of biological and nonbiological factors in the timing of relapse remains an outstanding question. In this study, we show that multiple sociodemographic features are associated with rrTNBC. In both the training and validation cohorts, the performance of our multivariable model was remarkably consistent but remained modest to predict rrTNBC (AUC, 0.76-0.77). In parallel genomic analyses, transcriptional programs and DNA alterations that are associated with this poor-prognosis subset of TNBCs were successfully identified; however, a multi-omic predictor had similar predictive capacity $(\sim 0.76-0.78) .{ }^{13}$ This finding suggests that both nonbiological 
A

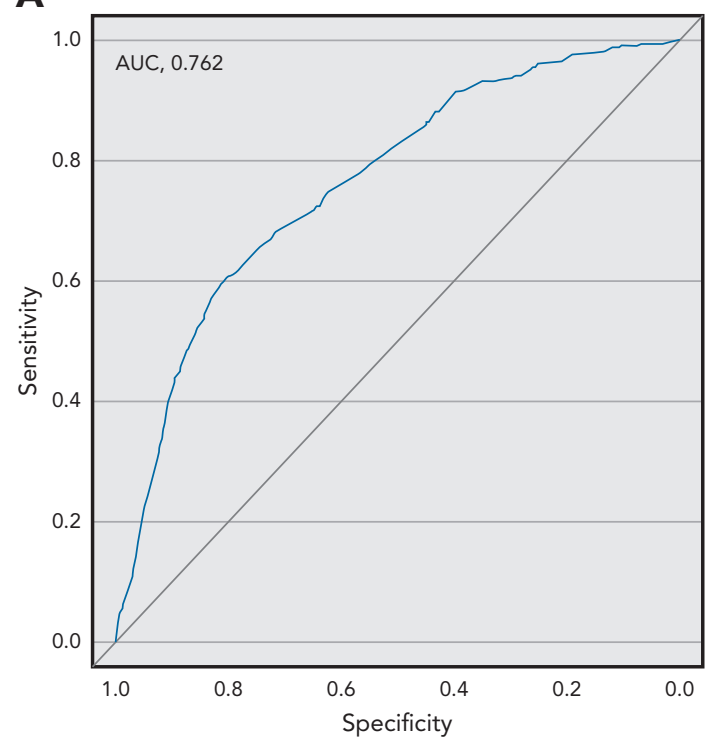

B

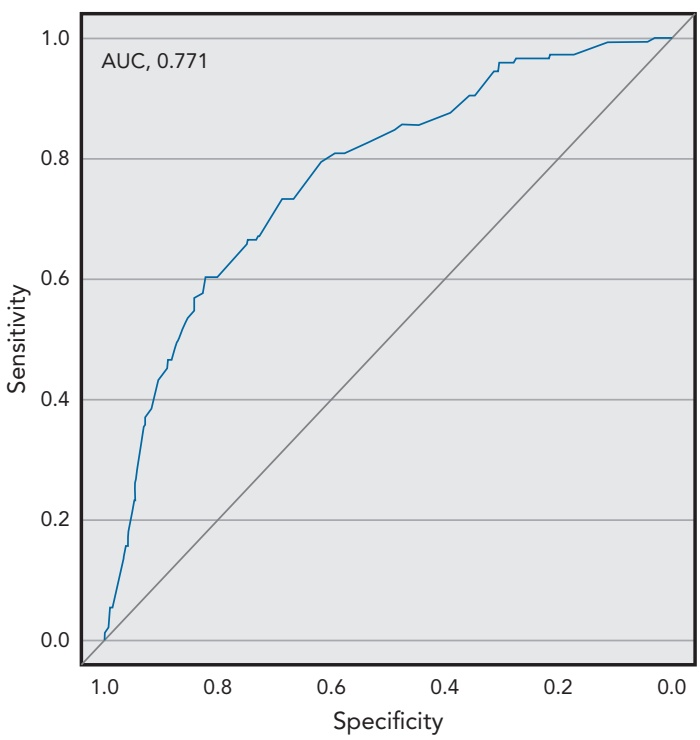

Figure 2. Model performance $A U C$ in $(A)$ training and $(B)$ validation cohorts. AUC statistics are indicated.

Abbreviation: AUC, area under the curve.

and biological factors may impact relapse in TNBC. The current analysis also does not address the known genomic intertumor and intratumor heterogeneity. ${ }^{29-32} \mathrm{~A}$ comprehensive dataset that incorporates genomic data, detailed sociodemographic data, and adequate numbers of TNBCs would be required to definitively test

\section{Table 3. Sensitivity Analysis of Final Model

\begin{tabular}{|c|c|c|c|}
\hline \multirow[b]{2}{*}{ Correlate } & \multicolumn{2}{|c|}{$\begin{array}{c}\text { Stages I and II } \\
(n=2,333)\end{array}$} & $\begin{array}{l}\text { Stage II } \\
(n=683)\end{array}$ \\
\hline & aOR $(95 \% \mathrm{Cl})$ & $P$ Value & aOR $(95 \% \mathrm{Cl})$ \\
\hline
\end{tabular}

Insurance type

Managed care Ref

Ref

Medicare

$1.8(1.0-3.1)$

Medicaid/Indigent

Other

$1.8(1.2-2.9)$

$0.7(0.3-1.5)$

Median annual household income, USD ${ }^{a}$

\begin{tabular}{lcccc}
\hline Quartile 1 & $2.0(1.3-3.0)$ & .002 & $1.1(0.7-1.8)$ & .64 \\
\hline Quartile 2 & $1.5(0.9-2.3)$ & .09 & $1.0(0.7-1.7)$ & .86 \\
\hline Quartile 3 & $1.5(1.0-2.3)$ & .07 & $1.2(0.8-2.0)$ & .40 \\
\hline Quartile 4 & Ref & & Ref &
\end{tabular}

Age at diagnosis, $y$

\begin{tabular}{ccccc}
\hline$<50$ & $1.8(1.1-3.0)$ & .01 & $1.4(0.8-2.2)$ & .23 \\
\hline $50-59$ & $1.3(0.8-2.1)$ & .33 & $0.6(0.4-1.1)$ & .10 \\
\hline $60-69$ & $\operatorname{Ref}$ & & $\operatorname{Ref}$ & \\
\hline$\geq 70$ & $0.8(0.3-1.7)$ & .52 & $1.2(0.6-2.5)$ & .64
\end{tabular}

Abbreviation: aOR, adjusted odds ratio.

aCalculated with 2000 US Census. ${ }^{21}$ whether an integrated approach could enhance physicians' ability to identify patients at high risk of rrTNBC for potential intervention.

Black race was associated with a modestly higher odds of rrTNBC in the bivariable analyses, but this did not remain significant in multivariable models. Black race has been strongly associated with having TNBC in the outcomes database. ${ }^{2}$ This finding is consistent with other population-based studies and has significant implications for disparities in survival and outcomes. ${ }^{1,33}$ It has also been shown that among patients for whom chemotherapy would be standard of care, non-Hispanic Black patients had a significantly lower likelihood of receiving adjuvant chemotherapy. ${ }^{34}$ Furthermore, a previous analysis of NCCN data demonstrated that nonHispanic Black women had a significantly longer time to chemotherapy initiation, and this disparity was greater for women with Medicare versus commercial insurance. ${ }^{35}$

Chemotherapy is standard of care for TNBC, and we only included patients who received chemotherapy to ensure applicability to current management practices. Patients who did not receive chemotherapy (and were excluded) primarily represented an older group who were, as expected, more likely to have Medicare insurance, have a higher comorbidity score, and have a lower stage and histologic grade at diagnosis. In our sensitivity analysis of rapid versus late relapse, these features were correlated with late relapse. This finding suggests that including these patients would not likely change our conclusions; in fact, we may be underestimating the 


\begin{tabular}{|c|c|c|c|}
\hline & $\begin{array}{c}\text { Rapid } \\
\text { Relapse } \\
\text { n (\%) }\end{array}$ & $\begin{array}{c}\text { Late } \\
\text { Relapse } \\
\text { n (\%) }\end{array}$ & $\begin{array}{c}\text { Chi-Square } \\
P \text { Value }\end{array}$ \\
\hline \multicolumn{3}{|l|}{ Insurance type } & .03 \\
\hline Managed care & $324(64.7)$ & $213(63.0)$ & \\
\hline Medicare & $74(14.8)$ & $68(20.1)$ & \\
\hline Medicaid/Indigent & $75(15.0)$ & $32(9.5)$ & \\
\hline Other & $28(5.6)$ & $25(7.4)$ & \\
\hline \multicolumn{3}{|c|}{ Median annual household income, USD } & .54 \\
\hline Quartile 1 & $149(30.4)$ & $98(30.1)$ & \\
\hline Quartile 2 & $122(24.9)$ & $94(28.8)$ & \\
\hline Quartile 3 & $127(25.9)$ & $73(22.4)$ & \\
\hline Quartile 4 & $93(18.9)$ & $61(18.7)$ & \\
\hline \multicolumn{3}{|l|}{ Age at diagnosis, y } & .0006 \\
\hline$<50$ & $275(54.0)$ & $137(40.3)$ & \\
\hline $50-59$ & $122(24.0)$ & $100(29.4)$ & \\
\hline $60-69$ & $76(14.9)$ & $62(18.2)$ & \\
\hline$\geq 70$ & $36(7.1)$ & $41(12.1)$ & \\
\hline \multicolumn{3}{|l|}{ Stage at diagnosis } & $<.0001$ \\
\hline I & $30(5.9)$ & $48(14.1)$ & \\
\hline II & $198(38.9)$ & $188(55.3)$ & \\
\hline III & $281(55.2)$ & $104(30.6)$ & \\
\hline
\end{tabular}

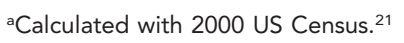

effect sizes seen. It is possible that there were variations in the type of chemotherapy or chemotherapy completion rate that we were unable to capture/analyze because of missing data. To address this concern, we did assess variations in the treatment of patients who received chemotherapy, and time from diagnosis to start of chemotherapy was not significantly different by age at diagnosis, insurance type, income, or race.

This cohort study has many strengths, including the large number of patients, diverse location of participating institutions, and detailed and uniform clinical abstraction. There are also limitations. Due to the nature of the data that were hospital-based, already abstracted, and fully deidenti- fied, we were limited by the variables and information of the data that were hospital-based, already abstracted, and fully deidentified, we were limited by the variables and information available. The cohort ceased enrollment in 2012, and standards of care may have shifted. We excluded patients who did not receive chemotherapy to avoid receipt of treatment as a significant confounder; however, relatively few patients in this cohort received neoadjuvant therapy $(25.2 \% ; 759 / 3,016)$, and we were unable to include specific chemotherapy regimens in our models. Our analysis did exclude patients from the original dataset with short follow-up to ensure that all patients in the primary analysis could be categorized as rrTNBC versus those who were not. Because of missing data, we used death from any cause instead of breast cancer-specific mortality; however, of the patients with $\operatorname{rrTNBC}$ with a cause of death, $97 \%$ died of their breast cancer.

\section{Conclusions}

In this large multi-institution study, we show that rrTNBC is associated with higher disease stage and distinct sociodemographic features, including insurance type, younger age at diagnosis, and income.

\section{Acknowledgments}

We wish to thank Catherine Carson, CNP; Krysten Brown, RN; Celia Garr, RN; and Katherine Tyson, RN, for clinical support, making this research possible.

Submitted March 30, 2020; final revision received September 22, 2020; accepted for publication September 23, 2020. Published online March 10, 2021

Author contributions: Study concept and design: Asad, Lin, Hassett, Stover. Data generation and coordination: Barcenas, Bleicher, Cohen, Javid, Levine, Lin, Moy, Niland, Wolff, Hassett, Stover. Writing - original draft: Asad, Stover Writing - review and editing: All authors.

Disclosures: Dr. Lin has reported receiving grant/research support from Genentech, Array Biopharma, GlaxoSmithKline, Kadmon, and Novartis. The remaining authors reported that they have not received any financial consideration from any person or organization to support the preparation, analysis, results, or discussion of this article.

Funding: This work was supported by a grant from Susan G. Komen for the Cure (CCR17480903; D.G. Stover).

Correspondence: Daniel G. Stover, MD, Stefanie Spielman Comprehensive Breast Center, Ohio State University Comprehensive Cancer Center, Biomedical Research Tower, Room 984, Columbus, OH 43210. Email: daniel.stover@osumc.edu

\section{References}

1. Bauer KR, Brown M, Cress RD, et al. Descriptive analysis of estrogen receptor (ER)-negative, progesterone receptor (PR)-negative, and HER2-negative invasive breast cancer, the so-called triple-negative phenotype: a populationbased study from the California Cancer Registry. Cancer 2007;109:1721-1728.

2. Lin NU, Vanderplas A, Hughes ME, et al. Clinicopathologic features, patterns of recurrence, and survival among women with triple-negative breast cancer in the National Comprehensive Cancer Network. Cancer 2012;118:5463-5472.

3. Lin NU, Claus E, Sohl J, et al. Sites of distant recurrence and clinical outcomes in patients with metastatic triple-negative breast cancer: high incidence of central nervous system metastases. Cancer 2008;113:2638-2645.

4. Kassam F, Enright K, Dent R, et al. Survival outcomes for patients with metastatic triple-negative breast cancer: implications for clinical practice and trial design. Clin Breast Cancer 2009;9:29-33.
5. Schmid P, Adams S, Rugo HS, et al. Atezolizumab and nab-paclitaxel in advanced triple-negative breast cancer. N Engl J Med 2018;379:2108-2121.

6. Dent R, Trudeau M, Pritchard Kl, et al. Triple-negative breast cancer: clinical features and patterns of recurrence. Clin Cancer Res 2007;13: 4429-4434.

7. Reddy SM, Barcenas $\mathrm{CH}$, Sinha AK, et al. Long-term survival outcomes of triple-receptor negative breast cancer survivors who are disease free at 5 years and relationship with low hormone receptor positivity. $\mathrm{Br} \mathrm{J}$ Cancer 2018;118:17-23.

8. Cancer Genome Atlas Network. Comprehensive molecular portraits of human breast tumours. Nature 2012;490:61-70.

9. Curtis $\mathrm{C}$, Shah SP, Chin SF, et al. The genomic and transcriptomic architecture of 2,000 breast tumours reveals novel subgroups. Nature 2012; 486:346-352. 
10. Stover DG, Coloff JL, Barry WT, et al. The role of proliferation in determining response to neoadjuvant chemotherapy in breast cancer: a gene expression-based meta-analysis. Clin Cancer Res 2016;22:6039-6050.

11. van Roozendaal LM, Smit LHM, Duijsens GHNM, et al. Risk of regional recurrence in triple-negative breast cancer patients: a Dutch cohort study. Breast Cancer Res Treat 2016;156:465-472.

12. Ghosh J, Agarwal S, Ganguly S, et al. Patterns of recurrence in triple negative breast cancer patients (automated $\mathrm{IHC}$ ): an Indian tertiary care center data [abstract]. J Clin Oncol 2018;36(Suppl):Abstract e13128.

13. Zhang $Y$, Nock W, Wyse $M$, et al. Machine learning predicts rapid relapse of triple negative breast cancer [preprint posted online April 21, 2019]. bioRxiv. doi: 10.1101/613604:613604

14. Hunter CP. Epidemiology, stage at diagnosis, and tumor biology of breast carcinoma in multiracial and multiethnic populations. Cancer 2000; 88(5 Suppl):1193-1202.

15. Lantz PM, Mujahid M, Schwartz K, et al. The influence of race, ethnicity, and individual socioeconomic factors on breast cancer stage at diagnosis. Am J Public Health 2006;96:2173-2178.

16. Schwartz KL, Crossley-May H, Vigneau FD, et al. Race, socioeconomic status and stage at diagnosis for five common malignancies. Cancer Causes Control 2003;14:761-766.

17. Harper S, Lynch J, Meersman SC, et al. Trends in area-socioeconomic and race-ethnic disparities in breast cancer incidence, stage at diagnosis, screening, mortality, and survival among women ages 50 years and over (1987-2005). Cancer Epidemiol Biomarkers Prev 2009;18:121-131.

18. Huo D, Hu H, Rhie SK, et al. Comparison of breast cancer molecular features and survival by African and European ancestry in The Cancer Genome Atlas. JAMA Oncol 2017;3:1654-1662.

19. Iqbal J, Ginsburg $O$, Rochon PA, et al. Differences in breast cancer stage at diagnosis and cancer-specific survival by race and ethnicity in the United States. JAMA 2015:313:165-173.

20. Vaz-Luis I, Ottesen RA, Hughes ME, et al. Outcomes by tumor subtype and treatment pattern in women with small, node-negative breast cancer: a multi-institutional study. J Clin Oncol 2014;32:2142-2150.

21. United States Census Bureau. By Decade: 2020. Accessed March 3, 2021. Available at: https://www.census.gov/programs-surveys/decennial-census/decade.html

22. Sparano J, O'Neill A, Alpaugh $K$, et al. Circulating tumor cells (CTCs) five years after diagnosis are prognostic for late recurrence in operable stage II-III breast cancer [abstract]. Cancer Res 2018;78(4 Suppl):Abstract GS6-03.
23. Dubsky P, Brase JC, Jakesz R, et al. The EndoPredict score provides prognostic information on late distant metastases in ER+/HER2- breast cancer patients. Br J Cancer 2013;109:2959-2964.

24. Sestak I, Cuzick J. Markers for the identification of late breast cancer recurrence. Breast Cancer Res 2015;17:10.

25. Booth CM, Li G, Zhang-Salomons J, et al. The impact of socioeconomic status on stage of cancer at diagnosis and survival: a population-based study in Ontario, Canada. Cancer 2010;116:4160-4167.

26. Aarts MJ, Voogd AC, Duijm LE, et al. Socioeconomic inequalities in attending the mass screening for breast cancer in the south of the Netherlands-associations with stage at diagnosis and survival. Breast Cancer Res Treat 2011;128:517-525.

27. Sprague BL, Trentham-Dietz A, Gangnon RE, et al. Socioeconomic status and survival after an invasive breast cancer diagnosis. Cancer 2011;117: 1542-1551.

28. Halpern MT, Bian J, Ward EM, et al. Insurance status and stage of cancer at diagnosis among women with breast cancer. Cancer 2007;110: 403-411.

29. Shah SP, Roth A, Goya R, et al. The clonal and mutational evolution spectrum of primary triple-negative breast cancers. Nature 2012;486: 395-399.

30. Navin N, Kendall J, Troge J, et al. Tumour evolution inferred by single-cell sequencing. Nature 2011;472:90-94.

31. Lehmann BD, Bauer JA, Chen $X$, et al. Identification of human triplenegative breast cancer subtypes and preclinical models for selection of targeted therapies. J Clin Invest 2011;121:2750-2767.

32. Lehmann BD, Jovanović $B$, Chen $X$, et al. Refinement of triple-negative breast cancer molecular subtypes: implications for neoadjuvant chemotherapy selection. PLoS One 2016;11:e0157368.

33. Carey LA, Perou CM, Livasy CA, et al. Race, breast cancer subtypes, and survival in the Carolina Breast Cancer Study. JAMA 2006;295: 2492-2502.

34. Brewster AM, Etzel C, Zhou R, et al. The impact of obesity on receipt of adjuvant chemotherapy for breast cancer in the National Comprehensive Cancer Network (NCCN) centers. Breast Cancer Res Treat 2011;130: 897-904.

35. Vandergrift JL, Niland JC, Theriault RL, et al. Time to adjuvant chemotherapy for breast cancer in National Comprehensive Cancer Network institutions. J Natl Cancer Inst 2013;105:104-112. 
Supplemental online content for:

\section{Sociodemographic Factors Associated With Rapid Relapse in Triple-Negative Breast Cancer: A Multi-Institution Study}

Sarah Asad, MPH; Carlos H. Barcenas, MD, MS; Richard J. Bleicher, MD; Adam L. Cohen, MD, MS; Sara H. Javid, MD; Ellis G. Levine, MD; Nancy U. Lin, MD; Beverly Moy, MD, MPH; Joyce Niland, PhD; Antonio C. Wolff, MD; Michael J. Hassett, MD, MPH; and Daniel G. Stover, MD

\section{J Natl Compr Canc Netw 2021;19(7):797-804}

eFigure 1: Directed Acyclic Graph Created Using the Training Dataset

eTable 1: Sensitivity Analysis of Final Model Comparing Adjusted Odds Ratios and Adjusted Risk Ratios

eTable 2: Characteristics of Women Diagnosed With TNBC From the NCCN Outcomes Database

eTable 3: Bivariable and Multivariable Analyses of Rapid Versus Non-Rapid Relapse 


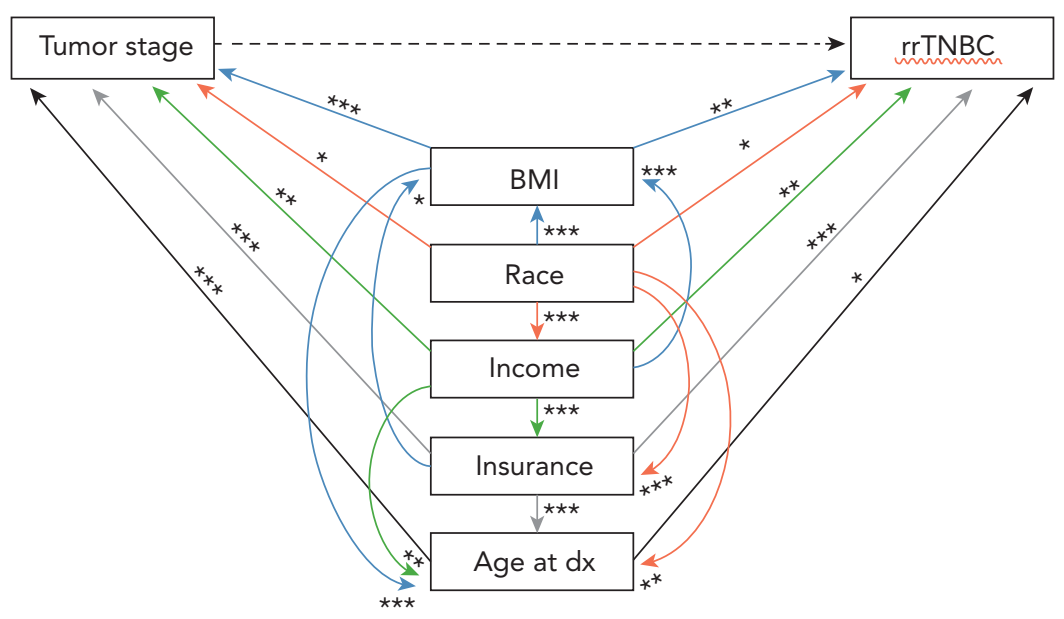

eFigure 1. Directed acyclic graph created using the training dataset. Any variable that was significantly associated $(P<.10)$ with tumor stage and significantly associated with rrTNBC in the bivariable analyses was included. Chi-square tests was used to assess each covariate of interest with tumor stage and rrTNBC. The main association of interest was tumor stage with rrTNBC. Directionality of association indicated by colored arrows. Abbreviations: BMI, body mass index; dx, diagnosis; rrTNBC, rapid-relapse triple-negative breast cancer.

${ }^{*}$ Chi-square $P<.05$

${ }^{*}$ Chi-square $P<.005$.

${ }^{* *}$ Chi-square $P<.0001$. 


\begin{tabular}{|c|c|c|c|c|}
\hline Correlate & aOR $(95 \% \mathrm{Cl})$ & $P$ Value & $\operatorname{aRR}(95 \% \mathrm{Cl})$ & $P$ Value \\
\hline \multicolumn{5}{|l|}{ Insurance type } \\
\hline Managed care & Ref & & Ref & \\
\hline Medicare & $1.5(0.9-2.4)$ & .14 & $1.2(0.9-1.8)$ & .23 \\
\hline Medicaid/Indigent & $1.6(1.1-2.4)$ & .01 & $1.3(1.1-1.7)$ & .02 \\
\hline Other & $1.0(0.5-1.8)$ & .93 & $1.0(0.6-1.5)$ & .96 \\
\hline \multicolumn{5}{|c|}{ Median annual household income, USD ${ }^{a}$} \\
\hline Quartile 1 & $1.5(1.0-2.2)$ & .04 & $1.2(1.0-1.6)$ & .12 \\
\hline Quartile 2 & $1.1(0.7-1.6)$ & .66 & $1.0(0.8-1.4)$ & .91 \\
\hline Quartile 3 & $1.3(0.9-1.9)$ & .14 & $1.2(0.9-1.6)$ & .17 \\
\hline Quartile 4 & Ref & & Ref & \\
\hline \multicolumn{5}{|l|}{ Age at diagnosis, y } \\
\hline$<50$ & $1.4(0.9-2.1)$ & .09 & $1.3(0.9-1.7)$ & .12 \\
\hline $50-59$ & $1.0(0.6-1.5)$ & .82 & $0.9(0.7-1.3)$ & .83 \\
\hline $60-69$ & Ref & & Ref & \\
\hline$\geq 70$ & $0.9(0.5-1.7)$ & .85 & $1.0(0.7-1.5)$ & .96 \\
\hline \multicolumn{5}{|l|}{ Stage at diagnosis } \\
\hline I & Ref & & Ref & \\
\hline II & $3.3(2.0-5.4)$ & $<.0001$ & $3.1(2.0-4.9)$ & $<.0001$ \\
\hline III & $16.0(9.8-26.2)$ & $<.0001$ & $9.9(6.3-15.4)$ & $<.0001$ \\
\hline
\end{tabular}

Abbreviations: aOR, adjusted odds ratio; aRR, adjusted risk ratio.

${ }^{a}$ Calculated with 2000 Census. Available at: https://www.census.gov/main/www/cen2000.html 


\begin{tabular}{|c|c|c|c|c|}
\hline & \multicolumn{2}{|c|}{ Training Cohort $(n=2,112)$} & \multicolumn{2}{|c|}{ Validation Cohort $(n=904)$} \\
\hline & $\begin{array}{c}\text { Not Rapid Relapse } \\
\text { n (\%) }\end{array}$ & $\begin{array}{c}\text { Rapid Relapse } \\
\text { n (\%) }\end{array}$ & $\begin{array}{c}\text { Not Rapid Relapse } \\
\text { n (\%) }\end{array}$ & $\begin{array}{c}\text { Rapid Relapse } \\
\text { n (\%) }\end{array}$ \\
\hline \multicolumn{5}{|l|}{ Study site ID } \\
\hline 1 & $102(5.81)$ & $19(5.32)$ & $44(5.85)$ & $11(7.24)$ \\
\hline 2 & $247(14.07)$ & $51(14.29)$ & $100(13.30)$ & $16(10.53)$ \\
\hline 3 & $170(9.69)$ & $40(11.20)$ & $76(10.11)$ & $15(9.87)$ \\
\hline 4 & $604(34.42)$ & $143(40.06)$ & $279(37.10)$ & $57(37.50)$ \\
\hline 5 & 207 (11.79) & $40(11.20$ & $67(8.91)$ & $7(4.61)$ \\
\hline 7 & $258(14.70)$ & 39 (10.92) & $122(16.22)$ & $28(18.42)$ \\
\hline 16 & $99(5.64)$ & $11(3.08)$ & $40(5.32)$ & $7(4.61)$ \\
\hline 17 & $23(1.31)$ & $5(1.40)$ & $6(0.80)$ & $3(1.97)$ \\
\hline 18 & $28(1.60)$ & $7(1.96)$ & $13(1.73)$ & $6(3.95)$ \\
\hline 19 & $17(0.97)$ & $2(0.56)$ & $5(0.66)$ & $2(1.32)$ \\
\hline \multicolumn{5}{|l|}{ Age at diagnosis, y } \\
\hline$<50$ & $814(46.38)$ & $186(52.10)$ & $343(45.61)$ & $89(58.55)$ \\
\hline $50-59$ & $537(30.60)$ & $88(24.65)$ & $246(32.71)$ & $34(22.37)$ \\
\hline $60-69$ & $314(17.89)$ & $56(15.69)$ & $124(16.49)$ & $20(13.16)$ \\
\hline$\geq 70$ & $90(5.13)$ & $27(7.56)$ & 39 (5.19) & $9(5.92)$ \\
\hline \multicolumn{5}{|l|}{ Race/Ethnicity } \\
\hline White, non-Hispanic & 1,277 (73.39) & $240(67.80)$ & $548(73.46)$ & $106(69.74)$ \\
\hline Black, non-Hispanic & 239 (13.74) & $66(18.64)$ & 107 (14.34) & $25(16.45)$ \\
\hline Hispanic/Other & $224(12.87)$ & $48(13.56)$ & $91(12.20)$ & $21(13.82)$ \\
\hline \multicolumn{5}{|l|}{ Education } \\
\hline$<$ High school & $109(7.68)$ & $24(8.54)$ & $42(6.89)$ & $8(6.61)$ \\
\hline High school & $344(24.24)$ & 78 (27.76) & $143(23.44)$ & $39(32.23)$ \\
\hline Some college, vocational/technical school & $404(28.47)$ & $78(27.76)$ & $182(29.84)$ & $28(23.14)$ \\
\hline College or higher & $562(39.61)$ & $101(35.94)$ & $243(39.84)$ & $46(38.02)$ \\
\hline \multicolumn{5}{|l|}{ Median annual household income, USD } \\
\hline Quartile 1 & $400(23.65)$ & $109(31.87)$ & $177(24.55)$ & $40(26.85)$ \\
\hline Quartile 2 & $425(25.13)$ & $79(23.10)$ & $175(24.27)$ & $43(28.86)$ \\
\hline Quartile 3 & $430(25.43)$ & $89(26.02)$ & $171(23.72)$ & $38(25.50)$ \\
\hline Quartile 4 & $436(25.78)$ & $65(19.01)$ & $198(27.46)$ & $28(18.79)$ \\
\hline \multicolumn{5}{|l|}{ Insurance type } \\
\hline Managed care & $1,274(73.22)$ & $219(62.04)$ & $555(74.50)$ & 105 (70.95) \\
\hline Medicare & $219(12.59)$ & $56(15.86)$ & $84(11.28)$ & $18(12.16)$ \\
\hline Medicaid/Indigent & $131(7.53)$ & $57(16.15)$ & $51(6.85)$ & $18(12.16)$ \\
\hline Other & $116(6.67)$ & $21(5.95)$ & $55(7.38)$ & $7(4.73)$ \\
\hline \multicolumn{5}{|l|}{$\mathrm{BMI}, \mathrm{kg} / \mathrm{m}^{2}$} \\
\hline$<18.5$ & $160(9.12)$ & $20(5.60)$ & $62(8.24)$ & $12(7.89)$ \\
\hline $18.5-24.9$ & $574(32.71)$ & $93(26.05)$ & 215 (28.59) & $37(24.34)$ \\
\hline $25.0-29.9$ & $478(27.24)$ & $104(29.13)$ & $230(30.59)$ & $48(31.58)$ \\
\hline$\geq 30.0$ & 543 (30.94) & $140(39.22)$ & 245 (32.58) & $55(36.18)$ \\
\hline
\end{tabular}


eTable 2. Characteristics of Women Diagnosed With TNBC From the NCCN Outcomes Database (cont.)

\section{Training Cohort $(n=2,112)$}

Not Rapid Relapse

n (\%)

$1,379(78.58)$

$246(14.02)$

$130(7.41)$

\begin{tabular}{|c|c|c|c|c|}
\hline I & $516(29.40)$ & $22(6.16)$ & $229(30.45)$ & $8(5.26)$ \\
\hline II & 959 (54.64) & $141(39.50)$ & 401 (53.32) & $57(37.50)$ \\
\hline III & 280 (15.95) & $194(54.34)$ & $122(16.22)$ & $87(57.24)$ \\
\hline \multicolumn{5}{|c|}{ istologic grade } \\
\hline 1 & $7(0.55)$ & $1(0.38)$ & $6(1.09)$ & $1(0.90)$ \\
\hline 2 & $122(9.67)$ & $23(8.81)$ & 59 (10.75) & $8(7.21)$ \\
\hline 3 & 1,133 (89.78) & $237(90.80)$ & 484 (88.16) & 102 (91.89) \\
\hline
\end{tabular}

959 (54.64)

280 (15.95)

III

Histologic grade

\begin{tabular}{|c|c|c|c|c|}
\hline I & $516(29.40)$ & $22(6.16)$ & $229(30.45)$ & $8(5.26)$ \\
\hline II & 959 (54.64) & 141 (39.50) & $401(53.32)$ & $57(37.50)$ \\
\hline III & 280 (15.95) & $194(54.34)$ & $122(16.22)$ & $87(57.24)$ \\
\hline \multicolumn{5}{|c|}{ istologic grade } \\
\hline 1 & $7(0.55)$ & $1(0.38)$ & $6(1.09)$ & $1(0.90)$ \\
\hline 2 & $122(9.67)$ & $23(8.81)$ & $59(10.75)$ & $8(7.21)$ \\
\hline 3 & 1,133 (89.78) & $237(90.80)$ & 484 (88.16) & 102 (91.89) \\
\hline
\end{tabular}

Abbreviation: BMI, body mass index.

aCalculated with 2000 Census. Available at https://www.census.gov/main/www/cen2000.html

\section{Validation Cohort $(n=904)$}

Not Rapid Relapse

n (\%)

Rapid Relapse

n (\%)

n (\%)

$275(77.03)$

601 (79.92)

121 (79.61)

57 (15.97)

98 (13.03)

$19(12.50)$

25 (7.00)

$53(7.05)$

12 (7.89)

Stage at diagnosis 


\begin{tabular}{|lc}
\hline eTable 3. Bivariable and Multivariable Analyses \\
\hline Correlate & OR \\
\hline Study site ID & Re \\
\hline 1 & 1. \\
\hline 2 & 1.3 \\
\hline 3 & 1.3 \\
\hline 4 & 1.0 \\
\hline 7 & 0.8 \\
\hline 16 & 0.6 \\
\hline 17 & 1.2 \\
\hline 18 & 1.3 \\
\hline 19 & 0.6
\end{tabular}

BMI, $\mathrm{kg} / \mathrm{m}^{2}$

\begin{tabular}{lc}
$<18.5$ & 0.8 \\
\hline $18.5-24.9$ & $R$ \\
\hline $25.0-29.9$ & 1.3 \\
$\geq 30.0$ & 1.6
\end{tabular}

$0.8 \quad .32$

32

0.9

.74

$1.3 \quad .06$

Ref

1.6

.06

1.1

.002

1.3

Race/Ethnicity

White, non-Hispanic Ref

Black, non-Hispanic

1.5
1.1

Hispanic/Other

.01

Ref

Comorbidity score

\begin{tabular}{ll}
0 & Ref \\
\hline 1 & 1.2 \\
$\geq 2$ & 1.0
\end{tabular}

Ref

1.2

1.0

.45

1.1

0.9

Multivariable

Education

\begin{tabular}{lcc}
\hline$<$ High school & 1.2 & .42 \\
\hline High school & 1.3 & .16 \\
\hline Some college, vocational/technical school & 1.1 & .66 \\
\hline College or higher & Ref
\end{tabular}

Median annual household income, USD ${ }^{a}$

\begin{tabular}{lllll} 
Quartile 1 & 1.8 & .0004 & 1.4 & 1.1 \\
\hline Quartile 2 & 1.2 & .22 & 1.3 & .74 \\
\hline Quartile 3 & 1.4 & .06 & Ref & .12 \\
\hline Quartile 4 & Ref & &
\end{tabular}

Insurance type

\begin{tabular}{lcccc}
\hline Managed care & Ref & Ref & \\
\hline Medicare & 1.5 & .02 & 1.5 & .14 \\
\hline Medicaid/Indigent & 2.5 & $<.0001$ & 1.7 & .007 \\
\hline Other & 1.1 & .83 & 1.0 & .96 \\
\hline
\end{tabular}

Other

1.1

.42
.16
.66

.35

.87

.69

(continued on next page) 
6 - Asad et al

\begin{tabular}{|c|c|c|c|c|}
\hline \multirow[b]{2}{*}{ Correlate } & \multicolumn{2}{|c|}{ Bivariable } & \multicolumn{2}{|c|}{ Multivariable } \\
\hline & OR & $P$ Value & OR & $P$ Value \\
\hline \multicolumn{5}{|c|}{ Age at diagnosis, y } \\
\hline$<50$ & 1.3 & .14 & 1.5 & .08 \\
\hline $50-59$ & 0.9 & .65 & 0.9 & .82 \\
\hline $60-69$ & Ref & & Ref & \\
\hline$\geq 70$ & 1.7 & .05 & 1.0 & .96 \\
\hline \multicolumn{5}{|c|}{ Stage at diagnosis } \\
\hline 1 & Ref & & Ref & \\
\hline$\|$ & 3.4 & $<.001$ & 3.2 & $<.0001$ \\
\hline III & 16.3 & $<.001$ & 15.4 & $<.0001$ \\
\hline \multicolumn{5}{|c|}{ Histologic grade } \\
\hline 1 & 0.7 & .72 & - & \\
\hline 2 & 0.9 & .66 & - & \\
\hline 3 & Ref & & - & \\
\hline \multicolumn{5}{|c|}{ Adjuvant radiation therapy } \\
\hline No & Ref & & - & \\
\hline Yes & 0.9 & .87 & - & \\
\hline
\end{tabular}

Abbreviations: BMI, body mass index; OR, odds ratio.

${ }^{a}$ Calculated with 2000 Census. Available at: https://www.census.gov/main/www/cen2000.html 